\title{
THF, COMMON STRENGTHENING EFFECT OF PHOSPHORUS, SULFUR, AND SILICON IN LOWER CONTENTS AND A PROBLEM OF A NET SUPERALLOY
}

\author{
W. R. Sun, S. R. Guo, J. T. Guo, B. Y. Tong, Y. S. Yang, X. F. Sun, H. R. Guan, Z. Q. Hu \\ Department of Superalloys and Special Castings, \\ Institute of Metal Research, Chinese Academy of Sciences \\ 72 Wenhua Road, Shenyang 110015, P. R. Chinà
}

\begin{abstract}
The effects of phosphorus, sulfur, and silicon on the microstructure and the stress rupture properties of a $\mathrm{Ni}-\mathrm{Fe}$ base superalloy were studied. Phosphorus had no effect on the grain size of the alloy, but sulfur reduced and silicon enlarged the grain size of the alloy. The 'net' alloy with the lowest amount of the minor elements had a problem of short rupture life. It was determined by analysis that the dislocations in the 'net' alloy were not firmly pinned by the segregation of the minor elements and could move easily, which increased the creep rate and reduced the rupture life of the alloy. In this case, a small addition of any minor element resulted in the same effect, significantly increasing the rupture life but drastically decreasing the rupture elongation. The concentration of the minor elements at the dislocations might reach the saturation point at a very low addition level. When the addition of the minor elements was above the level, their effect of inhibiting the dislocation movement did not increase again, and other influencing mechanisms by the elements took effect. Phosphorus had an effect to resist the intergranular ingression of the environmental oxygen. But the oxygen ingression along the grain boundaries was not the dominant factor leading to the
\end{abstract}

failure of the 'net' alloy. Phosphorus at $0.016 \mathrm{wt}$. \% strengthened the alloy by a perfect combination of the three influencing mechanisms, including the inhibition of the dislocation movement, the improvement of the intergranular precipitation, and the resistance to the intergranular ingression of the environmental oxygen. And hence the alloy had the longest life. Sulfur and silicon seemed having only one beneficial effect of pinning the dislocations, and hence they increased the rupture life of the alloy in the very small addition ranges. Sulfur had an abnormal effect to improve the rupture elongation of the alloy because it reduced the grain size noticeably.

\section{Introduction}

Minor elements play diverse and great roles in determining the microstructure and performance of Ni-base superalloys. Great efforts have been made throughout the history of superalloys to reduce the negative roles and allow full play to the positive roles of the minor elements. Several review papers [1-3] have summarized the major results up to 1984. Phosphorus, sulfur, and silicon are all classified as detrimental elements in these review papers. The effects of sulfur have been extensively studied and well documented. Gencrally speaking, sulfur reduces the ductility 
of superalloys by concentrating at the grain boundaries or forming the brittle $\mathrm{Y}-\mathrm{M}_{2} \mathrm{CS}$ phase [3]. Silicon has some solubility in Nibase superalloys and is detrimental to malleability even in small quantities. It reduces the workability of the alloys by forming the $\mathrm{M}_{6} \mathrm{C}$ phase or segregating at the grain boundaries. Si also forms the low melting point phases, such as Ni-Hf-Si, in superalloys [1]. Phosphorus has not been studied in detail and rare information can be retrieved from the literature up to 1984 . The maximum solubility of phosphorus in nickel is very small $(0.32 \%)$ and a eutectic exists at $875^{\circ} \mathrm{C}$. The addition of phosphorus to Inconel 600 causes the susceptibility to intergranular attack in strongly oxidizing media.

In the late eighties, some minor elements were suggested to be controlled as low as possible to get premium quality superalloys with homogeneous microstructure and mechanical properties. Because the elements, including phosphorus, sulfur, and silicon, tended to be segregated in the intcrdendritic areas and drop the finishing solidification temperature of the alloys [4-7]. But the study shows that the segregation tendency is different not only for different elements in the same alloy but also for the same element in different alloys [8]. For example, phosphorus can be dissolved into Laves phase and its effect on the solidification of Inconel 718 alloy can be neglected when its content is lowered to some extent.

Recently, great attentions have been paid to the influencing mechanism of phosphorus on superalloys, because phosphorus was found significantly prolonging the rupture life of some alloys [8-10]. Phosphorus tends to be segregated at the grain boundaries $[9,11]$. A strong interaction between phosphorus and boron has been found, and the interaction is an important, or even dominant factor that controlling the rupture life of the alloys [12, 13]. For example, the effect of phosphorus in alloy Waspaloy directly relies on the addition of boron [12]. A beneficial effect of phosphorus on the rupture life of the alloys comes from its improvement of the intergranular precipitation, by lowering the surface energy of the grain boundaries and interacting with carbon and boron $[14,15]$. In Inconel 718 alloy, phosphorus was found to resist the environmental oxygen attack efficiently [15]. In China, Xie's group carried out a series of works to study and compare the effects of phosphorus in $\mathrm{Ni}-\mathrm{Cr}-\mathrm{Fe}$, Ni-Cr-Fe-Mo and $\mathrm{Ni}-\mathrm{Cr}-$ Fe-Mo-Nb-Ti-Al systems [16-18]. The co-segregation of phosphorus, chromium and molybdenum has been detected at the grain boundaries [11], and a new point was raised that the abnormal effect of phosphorus might result from the effect of $P$ GB-Mo or P-GB-M (metal element) complex on the binding strength and ductility behavior of the grain boundaries. The assumption is supported by the results of the theoretical analysis and calculations [19]. The results and assumption demonstrate that phosphorus is not so poisonous in superalloys as in steels and supply with us the basis of employing phosphorus as a strengthening element but not a harmful one.

The effects of phosphorus, sulfur, and silicon on the microstructure and stress rupture properties of the alloy were investigated and compared in this study. The goal of this paper is to manifest the influencing mechanism of these elements.

\section{Materials and Experimental}

The materials were prepared in a vacuum induction furnace using high-purity raw materials. To minimize the compositional variations among the heats, the master alloy was prepared, and its composition (wt. \%) was C0.011, Cr12.89, Ni43.54, W3.12, Mo1.59, A11.71, Ti3.64, B0.003, Si0.059, S0.003, and Fe balance. And the master alloy was remelted to give ten $10 \mathrm{~kg}$ ingots. The ingots were added into different contents of phosphorus, sulfur, and silicon, with the same content of carbon and boron. The remelting also made the alloy much more homogeneous. The contents of carbon, boron, phosphorus, sulfur, and silicon were analyzed and are listed in Table 1.

The ingots were forged into bars of $45-\mathrm{mm}$-square section at $1120^{\circ} \mathrm{C}$, and rolled into round bars of $18 \mathrm{~mm}$ in diameter. These materials were then given a standard heat treatment of $1120^{\circ} \mathrm{C} / 2 \mathrm{~h}$, water cooled; $850^{\circ} / 4 \mathrm{~h}$, air cooled; and $750^{\circ} \mathrm{C} / 24 \mathrm{~h}$, air cooled.

The microstructure was observed by using optical microscopy, transmission electron microscopy (TEM), and scanning electron microscopy (SEM). Phase identification was mainly carried out using selected area diffraction. And the trace phases were analyzed by x-ray diffraction (XRD) after anodic matrix dissolution. An electron microprobe was used to measure the composition of precipitates.

The stress rupture lives and elongation of the alloys were measured at $650^{\circ} \mathrm{C}$ under constant load of $637 \mathrm{MPa}$, and the 
fracture surfaces of the test pieces were examined by SEM.

Table 1. Contents of Carbon, Boron, Phosphorus, Sulfur,

\begin{tabular}{c|lllll}
\multicolumn{5}{c}{ and Silicon of the Alloys (wt. \%) } \\
\hline Alloy & $\mathrm{P}$ & $\mathrm{S}$ & $\mathrm{Si}$ & $\mathrm{C}$ & $\mathrm{B}$ \\
\hline 1 & 0.0005 & 0.002 & 0.070 & 0.038 & 0.0049 \\
\hline 2 & 0.0009 & $0.002^{*}$ & $0.070^{*}$ & 0.039 & 0.0044 \\
\hline 3 & 0.016 & $0.002^{*}$ & $0.070^{*}$ & 0.041 & 0.0045 \\
\hline 4 & 0.051 & $0.002^{*}$ & $0.070^{*}$ & 0.036 & 0.0047 \\
\hline 5 & $0.0005^{*}$ & 0.0085 & $0.070^{*}$ & 0.040 & 0.0047 \\
\hline 6 & $0.0005^{*}$ & 0.017 & $0.070^{*}$ & 0.042 & 0.0045 \\
\hline 7 & $0.0005^{*}$ & 0.046 & $0.070^{*}$ & 0.042 & 0.0052 \\
\hline 8 & $0.0005^{*}$ & $0.002^{*}$ & 0.083 & 0.041 & 0.0050 \\
\hline 9 & $0.0005^{*}$ & $0.002^{*}$ & 0.38 & 0.047 & 0.0042 \\
\hline 10 & $0.0005^{*}$ & $0.002 *$ & 0.91 & 0.039 & 0.0045 \\
\hline
\end{tabular}

*not added when remelting and kept at the

lowest level as in the no.1 alloy

\section{Results and Discussion}

As shown in Fig.1, phosphorus scarcely affected the grain size of the alloys (see Figs. 1a and 1b). Comparatively, sulfur noticeably decreased the grain size (see Figs. 1a and 1c), and silicon increased the grain size when its content was as high as 0.91 wt. \% (see Figs. 1a and 1d). The precipitate lines were observed sometimes lying in the rolling directions. Phosphorus had little or no effect on the appearance of the precipitate lines. However, sulfur increased, and silicon decreased the appearance of the precipitate lines.

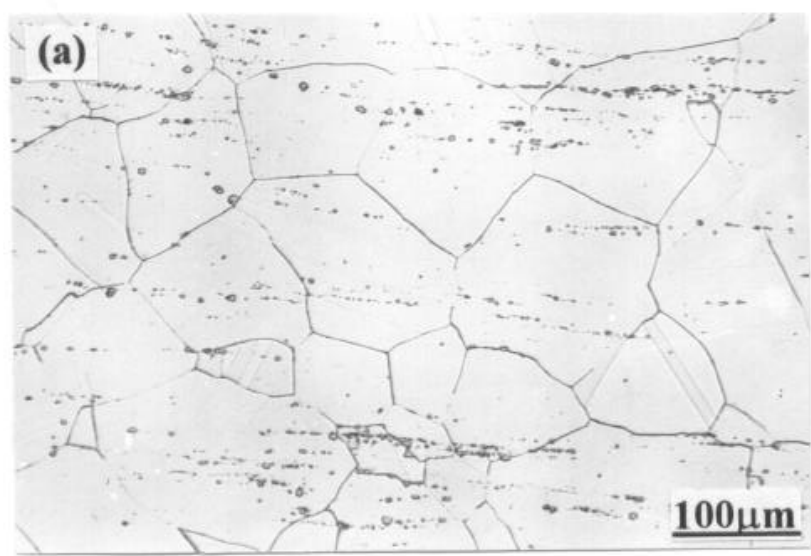

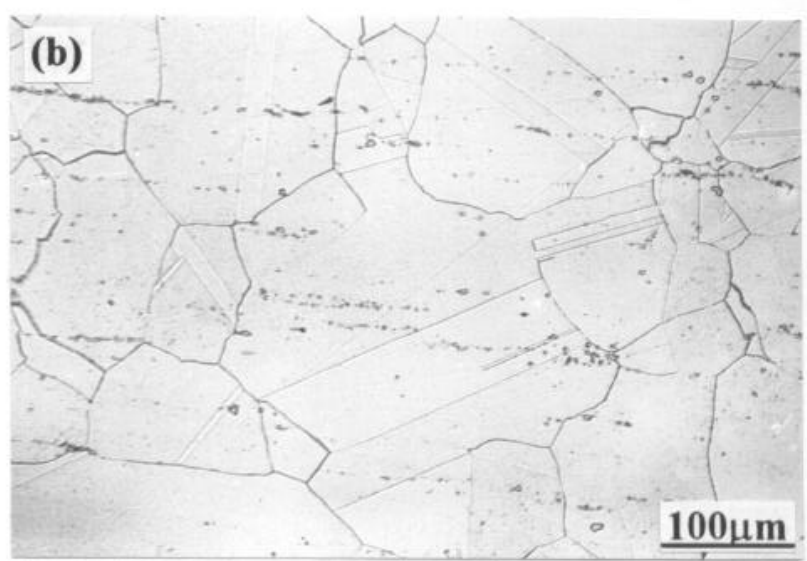
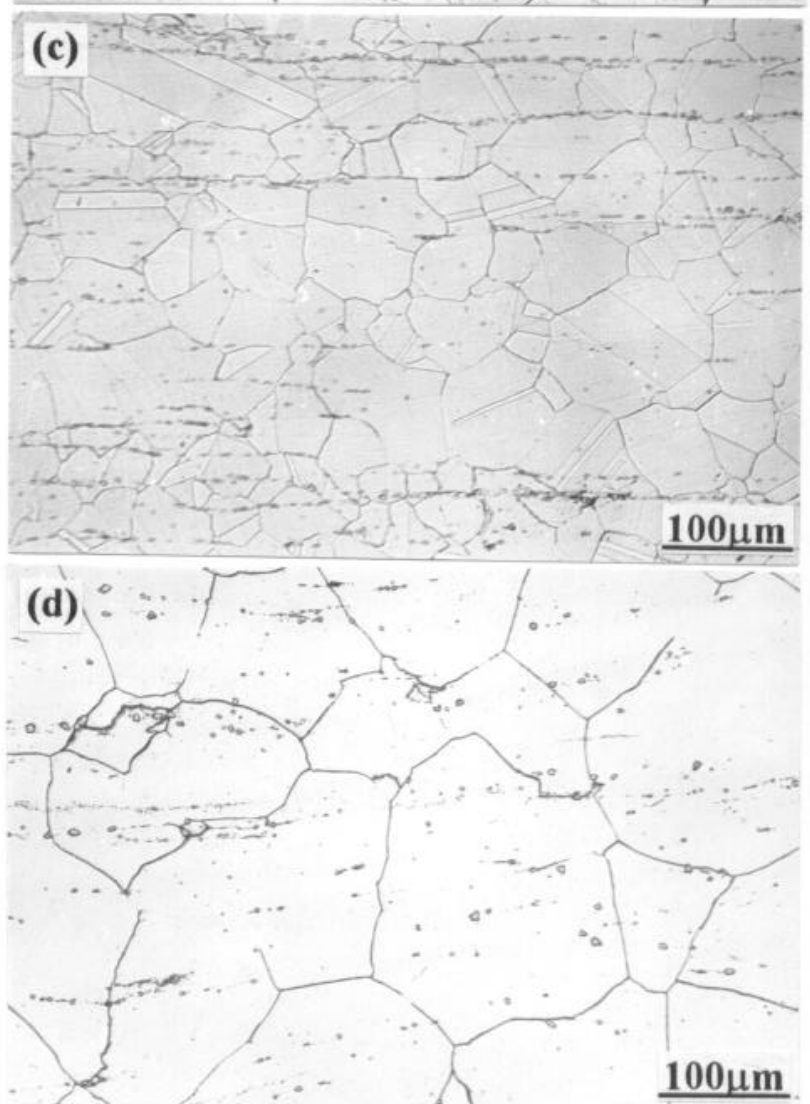

Fig.1 Effect of phosphorus, sulfur and silicon on the microstructure of the alloys. (a) no.1 alloy; (b) no. 4 alloy; (c) no.7 alloy; (d) no.10 alloy

By using XRD, it was determined that the trace phases were made up of the $\mathrm{MC}$ carbide, and a small amount of $\mathrm{M}_{3} \mathrm{~B}_{2}$ boride and $\mathrm{Y}$ $\mathrm{M}_{2} \mathrm{CS}$ sulfide. Phosphorus increased the precipitation of $\mathrm{M}_{23} \mathrm{C}_{6}$ carbide. The amount of $\mathrm{M}_{23} \mathrm{C}_{6}$ carbide was so low in the no.1 alloy that it was not detected by XRD. Sulfur naturally increased the precipitation of the $\mathrm{Y}-\mathrm{M}_{2} \mathrm{CS}$ phase. Silicon increased the precipitation of Laves phase and decreased the precipitation of MC carbide. 
The MC carbide precipitated at $1380^{\circ} \mathrm{C}$ during the solidification of the alloy. The influence of phosphorus and sulfur on the MC carbide crystallization could be neglected because the amounts of the residual liquids were large and hence the concentrations of the two elements in the liquids were lower at the temperature the carbide precipitated [8]. Silicon also had insignificant effect on the carbide precipitation when its content was lower than 0.38 wt. $\%$. However. the addition of silicon at 0.91 wt. \% decreased the carbide precipitation, and the primary Laves phase precipitated at $1100^{\circ} \mathrm{C}$ in the solidification of this alloy [8]. The $\mathrm{Y}-\mathrm{M}_{2} \mathrm{CS}$ phase precipitated at $1280^{\circ} \mathrm{C}$ in the solidification of the no. 1 alloy, and the precipitation temperature increased with the increasing sulfur content [8]

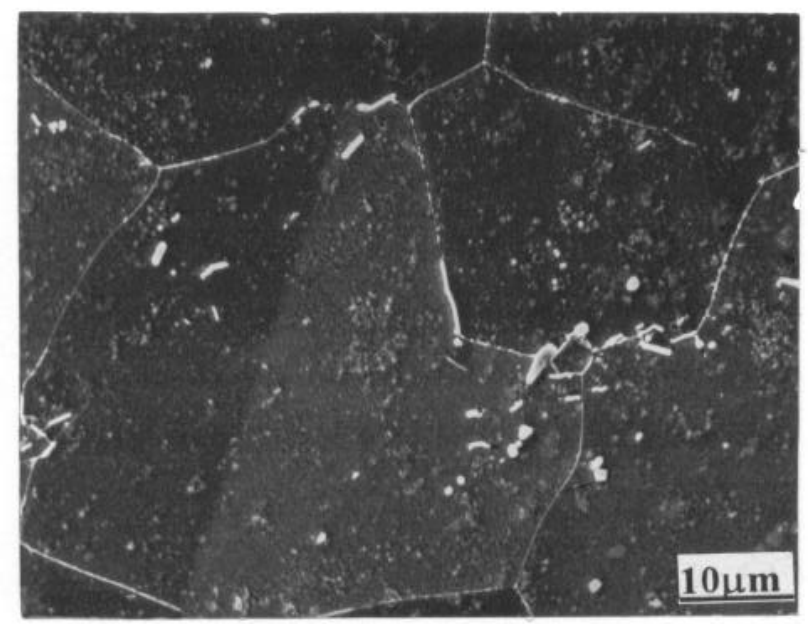

Fig.2 Distribution of $\mathrm{Y}-\mathrm{M}_{2} \mathrm{CS}$ phase in the no.7 alloy

The MC carbides were stable at the temperature that the thermal mechanical processing and the heat treatment were performed. They were broken into pieces by forging and rolling and distributed within the grain interior and on the grain boundaries. The recrystallization was inhibited by the MC carbide particles. Phosphorus did not affect the grain size of the alloys because it did not affect the precipitation of the primary MC carbide. The Y$\mathrm{M}_{2} \mathrm{CS}$ phase was also stable and the small rods of the broken pieces were also distributed within the grain interior or at the grain boundaries as shown in Fig.2. For this reason, sulfur noticeably reduced the grain size of the alloys. Comparatively, the primary Laves phase was not stable at the temperature of the thermal mechanical processing and the heat treatment, and it was dissolved while heating at $1120^{\circ} \mathrm{C}$ and failed to inhibit the recrystallization. As a result, silicon increased the grain size of the alloys. The Laves particles could only be observed on the grain boundaries, indicating that they were not the primary precipitates formed during the solidification.
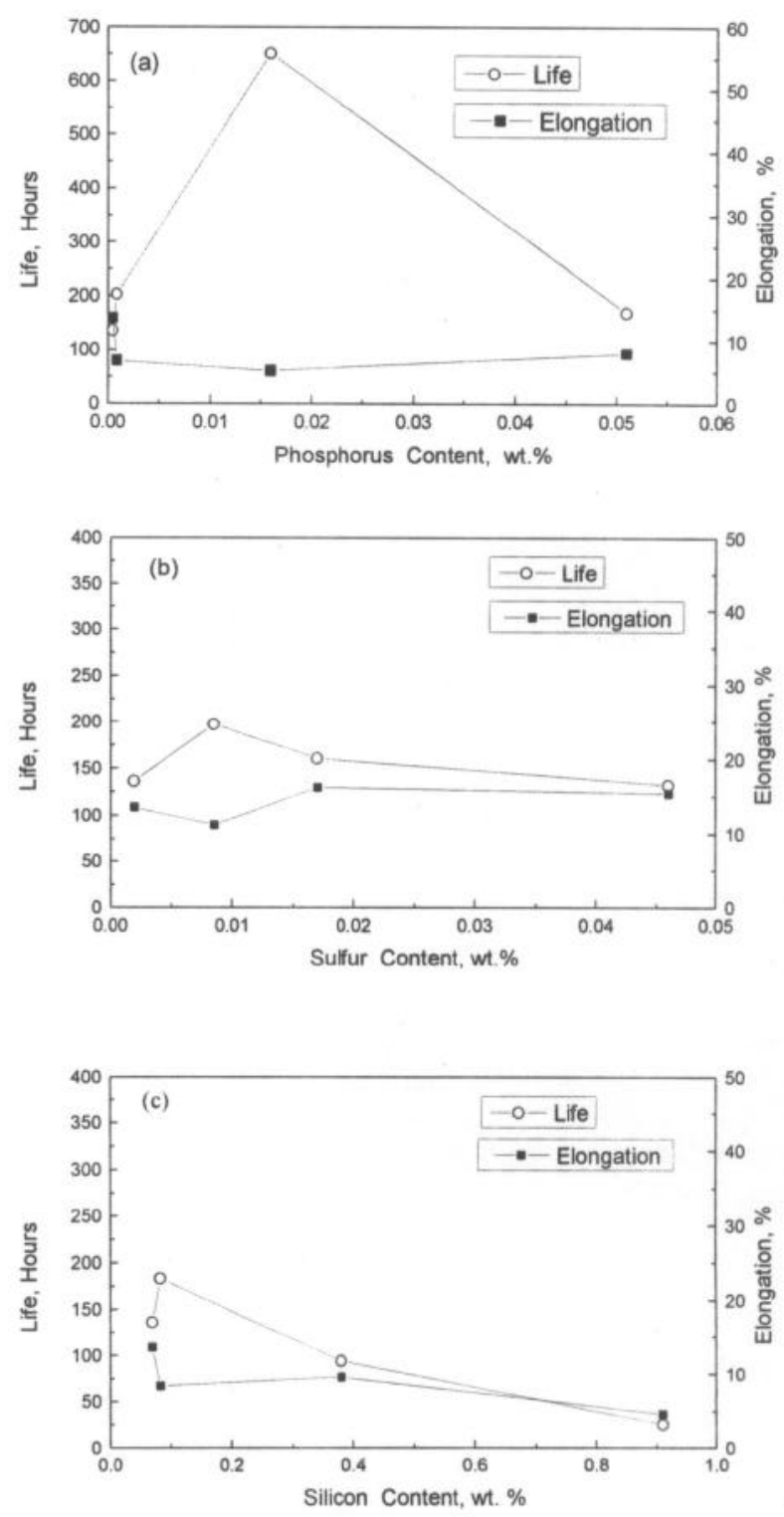

Fig. 3 Effect of phosphorus, sulfur, and silicon on the stress rupture properties of the alloys.

The effects of phosphorus, sulfur, and silicon on the stress rupture properties of the alloys are shown in Fig. 3. In some content ranges, phosphorus, sulfur and silicon all increased the rupture lives and simultaneously reduced the rupture elongation of the alloys. For the alloys added with phosphorus and sulfur, the longest lives are corresponded to the smallest elongation. For the alloys added with silicon, the situation is the same when the 
silicon content is lower than $0.35 \mathrm{wt} . \%$. It should be noted that all of the life lines go up with a significantly steep slope in the lower addition ranges (phosphorus 0.0005-0.0009 wt. \%; sulfur 0.0020.0085 ; silicon $0.070-0.083$ wt. \%) of the three elements, and correspondingly the elongation lines go down drastically. The results indicate that the three elements in their lower addition ranges might have a common influencing mechanism on the stress rupture properties of the alloys, though their influencing mechanisms are in general different from each other in the higher addition ranges.

The nickel-base superalloys obtain their high temperature strength mainly from three types of strengthening, including precipitation strengthening. solution strengthening and grain boundary strengthening. And the minor elements influence the stress rupture properties of the alloys mainly by modifying these strengthening mechanisms. The amount of the $\gamma^{\prime}$ phase was about $20 \mathrm{wt} . \%$ in this alloy, and phosphorus, sulfur and silicon slightly increased the particle size and precipitation amount of the $\gamma^{\prime}$ phase [14]. In the lower addition ranges, the effects of these elements on the $\gamma^{\prime}$ precipitation were insignificant and could be neglected. Therefore, it could be determined that the special significant effect of the three elements in the lower addition ranges was not originated from their influence on the precipitation strengthening mechanisms. Phosphorus, sulfur, and silicon are all surface-active elements, they tend to be segregated at the interfaces of various phases and the grain boundaries, and their concentrations in the $\gamma$ matrix are generally very small even when they are highly added. That is to say that the influence of the three elements in the lower addition ranges on the solution strengthening of the alloys was also not the reason for their common acute effect. The segregation of phosphorus, sulfur and silicon at the grain boundaries of superalloys has been verified by many previous studies $[9,11]$, and it was most possible that the great effects of the three elements in the lower addition ranges resulted from their modification on the grain boundary strength. However, this influencing mechanism was also impossible. For example, sulfur is typically a harmful element reducing grain boundary strength [3]. Phosphorus has a bad reputation to damage the grain boundary strength of steels. But both of them presented the same dramatic effect on the stress rupture properties in the lower addition ranges. The minor elements can also modify the grain boundary strength by affecting the grain boundary precipitation.
In the previous study of this alloy, phosphorus was found to increase the intergranular precipitation of $M_{23} C_{6}$ carbide and $M_{3} B_{2}$ boride, and it has been taken as one of the main reasons for phosphorus to prolong the rupture life of the alloy [14]. However, the observation showed that the intergranular precipitation of the alloy was scarcely changed when the phosphorus content is in the range of $0.0005-0.0009$ wt. \%. The addition of silicon in the range of $0.070-0.083$ also made no difference on the grain boundary precipitation. Because silicon increased the intergranular precipitation of the harmful Laves phase, it seemed impossible that the rapid increment of the rupture life was caused by the effect of silicon on the intergranular precipitation even if silicon did noticeably increase the grain boundary precipitation within such a small addition range. The effect of sulfur on the intergranular precipitation was more noticeable than that of phosphorus and silicon because it directly took part in the formation of $\mathrm{Y}-\mathrm{M}_{2} \mathrm{CS}$ phase. However, compared with phosphorus and silicon in their lower content ranges, the life line goes up and the elongation line goes down more slowly when the sulfur content is in the range of $0.002-0.0085$ wt. \% (see Fig.3). Apparently, the modification of the three elements on the intergranular precipitation was also not the reason for their common dramatic influencing mechanism on the stress rupture properties in the lower addition ranges.

The testing condition or the service environment is an important factor for determining the long-time properties, such as the stress rupture properties of the alloys. Phosphorus has been found to resist the grain boundary ingression of the environmental oxygen attack [15]. The similar effect was also found in this alloy, phosphorus greatly reduced the formation of the oxides at the grain boundaries on the surfaces of the specimens. However, it was at least not the main reason for phosphorus to increase the rupture life in the range of $0.0005-0.0009$ wt $\%$. If the intergranular ingression of the environmental oxygen was the predominant reason causing the premature failure of the stress rupture specimens, the cracks would form and propagate quickly along the grain boundaries and the deformation of the no.1 alloy should be smallest. However, the elongation of the no. 1 alloy was in fact the largest among the alloys added with phosphorus. The real process of the failure was that the opening of the surface grain boundaries caused the oxygen ingression and the oxidation, but not the contrary. Sulfur had no effect on the grain boundary 
oxidation. Although silicon efficiently resisted the oxidation of the alloys, its effect in the range of $0.070-0.083$ wt. \% was not noticeable. In addition, the silicon addition also reduced the rupture elongation of the alloys as phosphorus did. Therefore, the improvement of the environmental oxygen attack resistance by the three elements in the lower content ranges can also be determined not to be the reason for their common significant effect.

With the exception of the grain boundaries and the interfaces between the phases, the loose structures such as dislocations are also the places where the minor elements tend to be segregated. It is well known that phosphorus is prone to form 'atmosphere' at the dislocations in steels and cause temper brittleness. Because other possible influencing mechanisms have been excluded as above, the concentration of the three elements at the dislocations might be the true reason leading to their common significant effect in the lower content ranges. Because the total amount of the minor elements in the 'net' no.l alloy was so low, the concentration of the minor elements at the dislocations might not reach the saturation point. Without the pinning by the concentration of the minor elements, the dislocations moved easily, leading to the large deformation of the metals, the quick formation and propagation of the cracks at the grain boundaries, and the premature failure of the specimens. This explains the high rupture elongation of the no. 1 alloy. In this case, a small increment of the minor elements could greatly increase their concentrations at the dislocations. The pinning effect was thus quickly enhanced and the movement of the dislocations was efficiently inhibited. As a result, the deformation became more difficult and the creep rate was correspondingly slowed down. This accords well with the results shown in Fig.3 that the rupture lives were greatly increased and the rupture elongation largely reduced by a small addition of any of the three elements.

In addition, phosphorus and silicon existed most likely as free atoms instead of forming the precipitates when their contents were lower, and subsequently a small addition increment could result in a greater concentration increase at the dislocations. Sulfur formed the Y-M $\mathrm{M}_{2} \mathrm{CS}$ phase even when its content is as low as $0.002 \mathrm{wt}$ \% in the no.l alloy, and therefore the increment of sulfur content led to a relatively small increase of the sulfur concentration at the dislocations. As a result, the effect of sulfur was slighter than that of phosphorus and silicon in their lower content ranges (see Fig.3). This may be an extraneous evidence of the above assumption.

The concentration of any element at the dislocations resulted in the same pinning effect, this explains the common influence of the three elements in their lower content ranges.

As shown in the Fig.3a, after the very sharp increase of the rupture life in the range of $0.0005-0.0009 \mathrm{wt}$. \%, the increasing rate of the life line becomes lower when the phosphorus content is in the range of $0.0009-0.016$ wt. \%. Correspondingly, the elongation line shows an inverse tendency. Actually, the concentration of phosphorus at the dislocations might quickly reach the saturation point with a small increment of the phosphorus addition. With the further increment of the phosphorus addition, its effect on retarding the dislocation movement ceased to increase. In this case, other influencing mechanisms began to take effect. Except the effect of improving the resistance to the intergranular ingression of the environmental oxygen, phosphorus increased the intergranular precipitation noticeably [14].

Different from phosphorus, the rupture lives of the alloys added with sulfur and silicon began to reduce after the rapid increase in the lower content ranges. Sulfur had no effect on the intergranular ingression of the environmental oxygen, and the $\mathrm{X}-\mathrm{M}_{2} \mathrm{CS}$ phase was in general a harmful phase. Therefore, different from phosphorus, sulfur did not increase the rupture life of the alloys after its concentration at the dislocations reached saturation point. Silicon also reduced the rupture life of the alloys at a higher addition level because it increased the precipitation of harmful Laves phase.

Sulfur is typically a harmful element to reduce the plasticity of the alloys. However, it presented an abnormal effect to increase the elongation of this alloy as shown in Fig.3b. Sulfur mainly formed the $\mathrm{Y}-\mathrm{M}_{2} \mathrm{CS}$ phase. This greatly reduced its concentration at the grain boundaries and hence the plasticity of the alloy was not damaged largely by the segregation mechanism. But the formation of the $\mathrm{Y}-\mathrm{M}_{2} \mathrm{CS}$ phase largely decreased the grain size, and hence the rupture elongation was increased. 

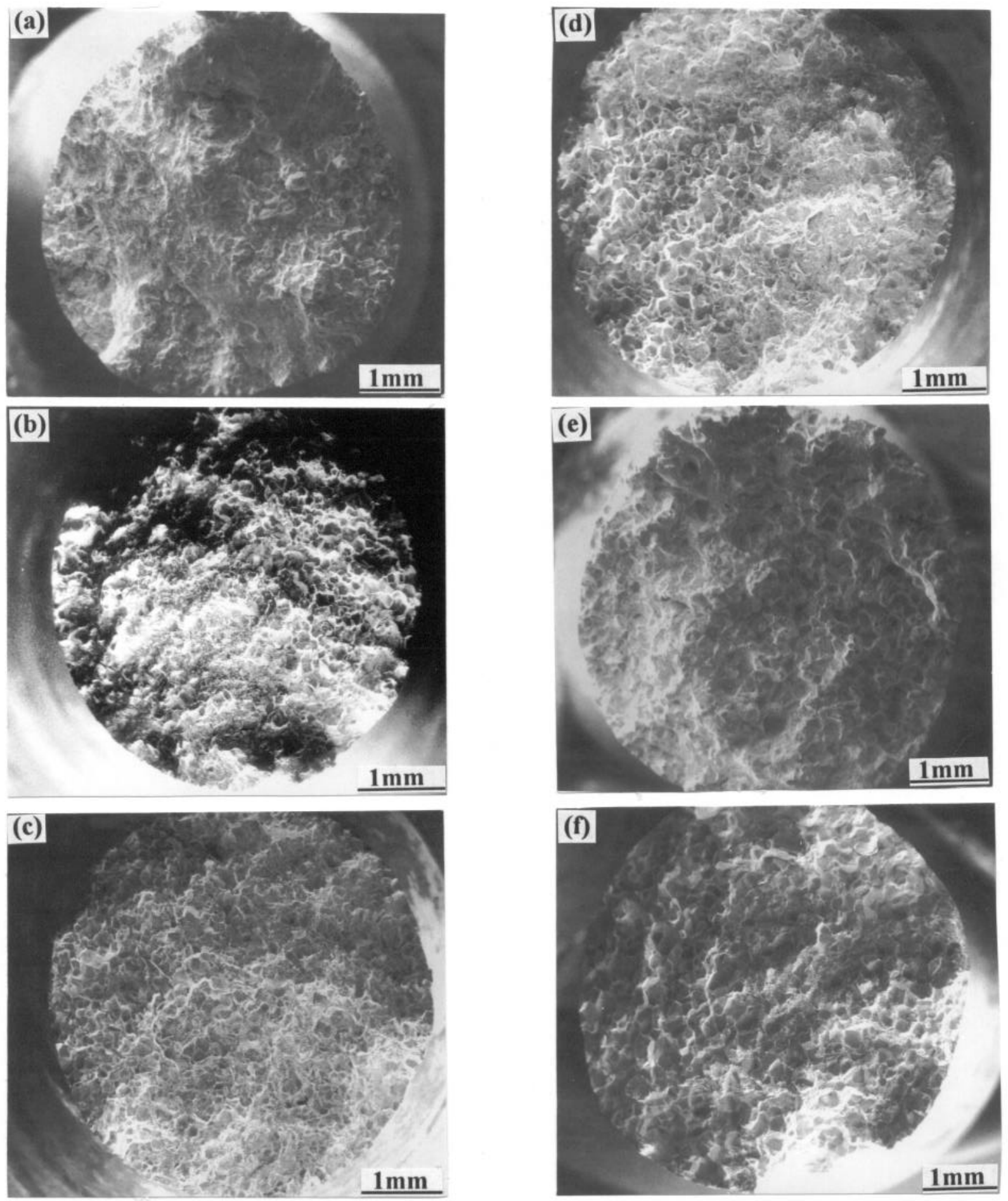

Fig.4 Effect of phosphorus, sulfur, and silicon on the fracture mode of the alloys

(a) no. 1 alloy; (b)no. 2 alloy; (c) no. 3 alloy

(d) no4 alloy; (e) no.9 alloy; (f) no10 alloy 
It is apparent that the 'net' superalloy had a problem of short life. When the alloy was very net or the total amount of the minor elements was very small, the dislocations could move easily. The cracks were quickly formed due to the rapid deformation of the grains, and they propagated rapidly because the grain boundaries were not sufficiently strengthened by the intergranular precipitation [14]. In this case, the increased addition of any minor element that tends to be segregated at the dislocations can efficiently prolong the rupture life but simultaneously reduce the rupture elongation of the alloy.

The fractographs of the alloys added with phosphorus are shown in Figs. $4 \mathrm{a}-4 \mathrm{~d}$. The fracture surface can be divided into two areas. One is the 'undulated area' with smooth exposing grain boundary surfaces. And the other is the 'flat area' where the detail character is not clearly shown at the lower magnification of Fig.4. The fine microstructure of the 'flat area' is shown in Figs. 5a and 5b, there are many small pits with a plastic tearing character on the area. In addition, in the flat area some of the grain boundaries perpendicular to the fracture surface are widened due to the oxidation (see Fig.5b). It is no doubt that the grain boundaries parallel to the fracture surfaces were more prone to be oxidized under load. Then the small pits on the fracture surface might not be the plastic tearing but the places where the particles of the oxides were formed and fell off when the samples were broken. The flat area was liable to be taken as the area that was finally pulled apart, because there are many small pits with a character looked like the plastic tearing. But it was actually the area where the grain boundaries were initially opened, and then oxidized while soaking at $650^{\circ} \mathrm{C}$ under the load.

It is shown in Fig.4c that most area of the fracture surface of the no.3 alloy is ' undulated area' with exposing grain boundary surface, indicating that the grain boundaries of the alloy were well prevented from the environmental oxygen ingression. But in Fig.4d, the fraction of the 'flat area' of the no. 4 alloy increased again. Considering that phosphorus increased the resistance to the environmental oxygen attack, the 'flat area' formed by the oxidation of the grain boundaries in the no. 4 alloy should be less than that in the no. 3 alloy. Actually, the grain boundaries in the no. 4 alloy were easy to open due to the excessive precipitation caused by the high addition of phosphorus [14]. The opened grain boundaries facilitated the oxygen ingression and hence led to the increased fraction of the flat area in the no. 4 alloy. This reflects that the improvement of the intergranular precipitation was the predominant influencing mechanism for phosphorus to prolong the rupture life of the alloy [14]. This also indicates that the segregation of phosphorus atom at the grain boundaries might not damage but increase the boundary strength [16-18]. Considering that the rupture life of the no. 3 alloy was more than 600 hours, the improvement of the resistance to the intergranular oxygen ingression must be a necessary factor for phosphorus to prolong the rupture life of the alloys. Apparently, phosphorus at 0.016 wt. $\%$ maximally strengthened the alloy by a perfect combination of its three influencing mechanisms, including the inhibition of the dislocation movement, the improvement of the intergranular precipitation, and the resistance of the environmental oxygen attack. And hence the no.3 alloy had the longest rupture life among all of the alloys studied.
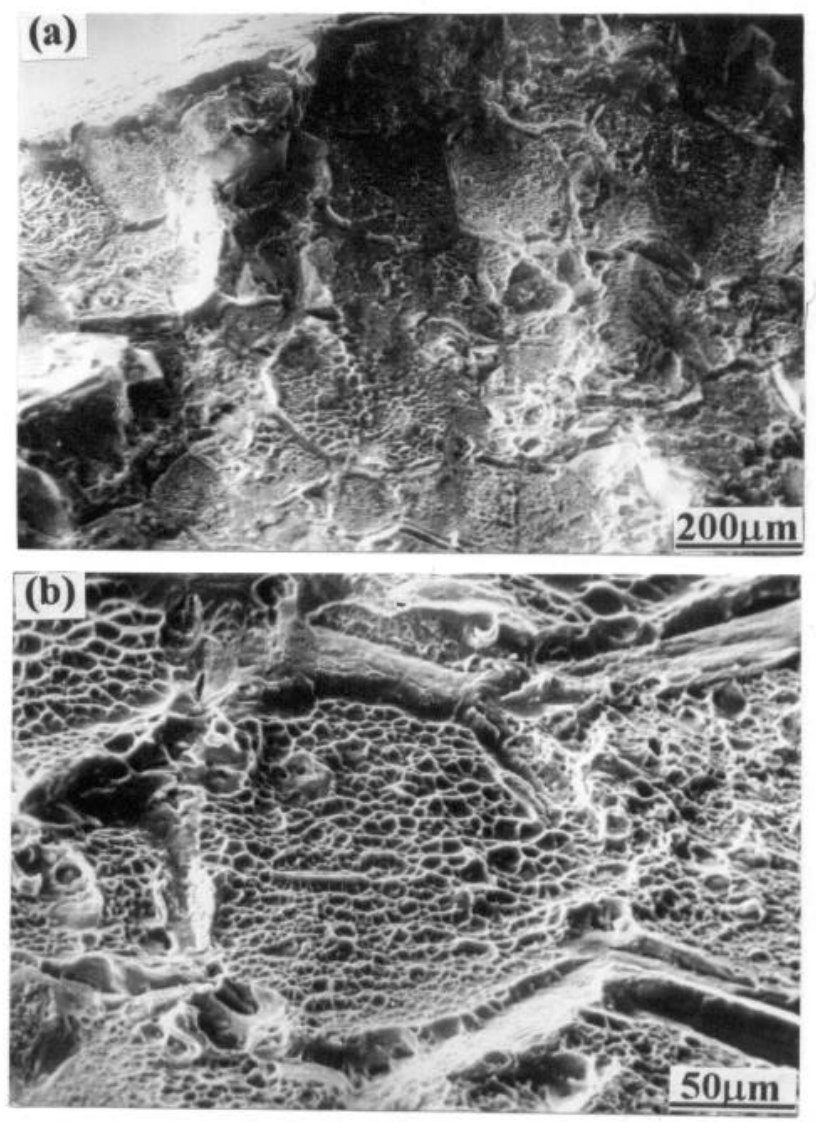

Fig.5: (a) Oxidized area on the fracture surface of the No.2 alloy

(b). An area from figure (a) at high magnification 
Because sulfur had no effect to resist the environmental oxygen attack, the fractographs of the alloys added with sulfur were similar with that of the alloys with a lower phosphorus addition. Because silicon increased the Laves precipitation, the cracks were easy to form at and propagate along the grain boundaries. The opened grain boundaries facilitated the oxygen ingression and hence the 'flat area' of the no.9 alloy was not reduced (see Fig.4e), though silicon had a noticeable effect to resist the oxidation. However, the 'flat area' of the no.10 alloy was reduced (see Fig.4f), though the cracks could form at and propagate along its grain boundaries more easily. This is for two reasons, one is that the rupture life of the no.10 alloy was very short, the other was that the resistance of silicon at $0.91 \mathrm{wt} \%$ to the oxidation is very high. As a result, the fracture surface of No. 10 alloy was very smooth as shown in Fig.6.

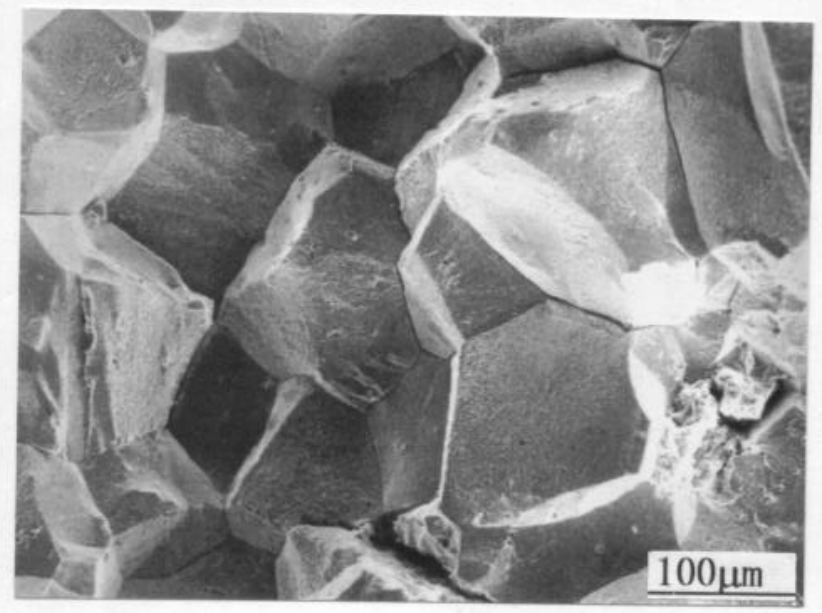

Fig.6 Smooth grain boundaries on the fracture surface of the no. 10 alloy

\section{Conclusions}

1. The recrystallization of the alloys was inhibited by the MC carbide. Phosphorus scarcely influenced the MC carbide precipitation and hence had no effect on the grain size. Silicon decreased the MC carbide precipitation and hence enlarged the grain size of the alloys. Sulfur reduced the grain size because the $\mathrm{Y}-\mathrm{M}_{2} \mathrm{CS}$ phase inhibited the recrystallization of the alloy.

2. The net superalloy with the lowest amount of the minor elements had a problem of short rupture life, because the dislocations in the alloy were easy to move without the pinning by the concentration of the minor elements. The addition of the minor elements in some lower content ranges significantly increased the rupture lives and drastically decreasing the rupture elongation of the alloys. The common significant effect of the minor elements was caused by their concentration at the dislocations which largely inhibited the dislocation movement.

3. Phosphorus influenced the rupture properties of the alloys mainly by three mechanisms, including the inhibition of the dislocation movement, the enhancement of the intergranular precipitation, and the resistance to the environmental attack. The alloy with 0.016 wt. \% phosphorus addition had the longest life due to the perfect combination of the three strengthening effect of phosphorus at this content.

4. Sulfur increased the rupture elongation because it reduced the grain size of the alloy. Silicon increased the intergranular precipitation of Laves phase but resisted the oxidation.

\section{Acknowledgement}

This work was founded by National Natural Science Foundation of China under the contract of No. 59801013

\section{References}

1. R. T. Holt and W. Wallace, "Impurities and trace elements in nickel-base superalloys," Intermational Metals Reviews, 21(1976), 1-24.

2. M. McLean and A. Strang, "Effect of trace elements on mechanical properties of superalloys," Metals Technology, 11(1984), 454-464.

3. G. W. Meetham, "Trace elements in superalloys-an overview," Metals Technology, 11 (1984), 414-418.

4. Y. Zhu et al., "A new Way to Improve the Superalloys," Superalloys 1992, Eds. S. D. Antolovich et al., (Warrendale, PA: The Minerals, Metals \& Materials Society, 1992), 145-154.

5. H. Q. Zhu et al., "The effect of silicon on the microstructure and segregation of directionally solidified IN738 superalloy," Materials at High Temperatures, 12 (4) (1994), 285-291. 
6. W. R. Sun et al., "Effect of sulfur on the solidification and segregation in Inconel 718 alloy," Materials Letters, 31 (1997), 195-200.

7. C. Chen, R. G. Thompson and D. W. Davis, "A Study of Effects of Phosphorus, Sulfur, Boron and Carbon on Laves and Carbide Formation in Alloy 718,"Superalloys 718, 625,706 and Various Derivatives. Ed. E. A. Loria, (Warrendale, PA: The Minerals, Metals \& Materials Society, 1991), 81-90.

8. Z. Q. Hu, W. R. Sun and S. R. Guo, "Effect of P, S and Si on the solidification, segregation, microstructure and mechanical properties in Fe Ni base superalloys," Acta Metallurgica Sinica, 9 (1996), 443-449.

9. W. D. Cao. and R. L. Kennedy, "The Effect of Phosphorus on the Mechanical Properties of Alloy 718," Superalloys 718,625. 706 and Various Derivatives, Ed. E. A. Loria, (Warrendale, PA: The Minerals, Metals \& Materials Society, 1994), 463.

10. Xishan Xie et al., "THE ROLE OF PHOSPHORUS AND SULFUR IN INCONEL 718," Superalloys 1996, Eds. R. D. Kissinger et al., (Warrendale, PA: The Minerals, Metals \& Materials Society, 1996). 599-606.

11. J. X. Dong et al., "The segregation of sulfur and phosphorus in nickel-base alloy 718." Acta Metallurgica Sinica, 10 (6) (1997), 510-514.

12. W. D. Cao and R. L. Kennedy, "Phosphorus and Boron Interaction in Nickel - Base Superalloys," Superalloys 1996, Eds. R. D. Kissinger et al., (Warrendale, PA: The Minerals, Metals \& Materials Society, 1996), 589-597.

13. Wei-Di Cao and R. L. Kennedy, "Effect and mechanism of phosphorus and boron on creep deformation of alloy 718 ," Superalloys 718,625.706 and Various Derivatives, Ed. E. A. Loria, (Warrendale, PA: The Minerals, Metals \& Materials Socicty, 1997), 511-520.

14. W. R. Sun et al., "Effect of phosphorus on the microstructure and stress rupture properties in an $\mathrm{Fe}-\mathrm{Ni}-\mathrm{Cr}$ base superalloy," Metallurgical and Materials Transactions, 28A (1997), 649-654.

15. W. R. Sun et al., "Effect of phosphorus on the $\delta-\mathrm{Ni}_{3} \mathrm{Nb}$ phase precipitation and stress rupture properties in alloy 718 ,"

$\because$ Materials Science and Engineering, A247 (1998), 173-179.
16. Xishan Xie et al., "Segregation behavior of phosphorus and its effect on microstructure and mechanical properties in alloy system Ni-Cr-Fe-Mo-Nb-Ti-Al," Superalloys 718, 625,706 and Various Derivatives, Ed. E. A. Loria, (Warrendale, PA: The Minerals, Metals \& Materials Society, 1997), 311-542.

17. Xishan Xie et al., "An abnormal effect of phosphorus on mechanical properties in nickel-base superalloys of $\mathrm{Ni}-\mathrm{Cr}-\mathrm{Fe}$, $\mathrm{Ni}-\mathrm{Cr}-\mathrm{Fe}-\mathrm{Mo}$ and Ni-Cr-Fe-Mo-Nb-Ti-Al system," The Third Pacific Rim International Conference on Advanced Materials and Progressing_(PRICM 3), Eds. M. A. Imam et al., (Warrendale, PA: The Minerals, Metals \& Materials Society, 1998), 215-222.

18. Xingbo Liu et al., "Investigation of the abnormal effects of phosphorus on mechanical properties of Inconel 718 superalloy," Materials Science and Engineering, A270 (1999), 190-196.

19. Xingbo Liu et al., "Molecular dynamics simulation on phosphorus behaviors at $\mathrm{Ni}$ grain boundary", (University of Science and Technology Beijing, to be published). 